\title{
Forced Choices: Role Play and the Problem of Disappearing Syntax ${ }^{1}$
}

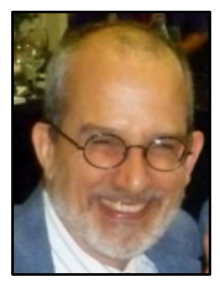

David Kellogg

Hankuk University of Foreign Studies, Republic of Korea

\begin{abstract}
We begin with the observation that some Korean elementary school children in English class, confined to a single situation and even a single language exponent in a role play, appear to produce far more coherent dialogue than the previous week when they were allowed completely free choices in language. We note that at the same time as their dialogue becomes longer, their sentences become shorter (tall and thinner on the printed page), and we suggest that the grammatical complexity is consciously unpacked as discourse complexity. When we turn to a large corpus of longitudinal and cross sectional data, we see, however, that "thinner" dialogue with short utterances is not always more creative, at least not grammatically. We see that the children are deliberately and consciously choosing more elliptical and less creative expressions when they speak. We generalize from this data to show that the problem is no mere artifact of the data sample. We theorize from this generalization to show that the development of the child's free will in syntax is related to a long chain of such constraints, leading from instincts to habits to intelligent choices oriented toward the immediate environment to acts of free will which are genuinely voluntary and which admit no sovereign but the child's developing self. Indeed, we shall argue that the exercise of this sovereignty is precisely how the child develops a self in the first place.
\end{abstract}

Keywords: dialogue; syntax; self

David Kellogg is an associate professor at the graduate school of TESOL in Hankuk University of Foreign Studies, where he teaches research methods, thesis writing, and a class on narrative and discourse on story-telling. He is currently involved in issuing the collected works of Vygotsky in the Korean language. His publications include more than two dozen articles in academic journals, including Modern Language Journal, Applied Linguistics, Language Teaching Research, Language and Education, Language Awareness, and Psyanima Psychological Journal. His forthcoming book, on Sense Publications, is "The Great Globe and All Who it Inherit", a book on narrative, discourse and story-telling.

\footnotetext{
${ }^{1}$ This research was made possible by a grant from the Hankuk University of Foreign Studies Research Fund, 2014.
} 


\title{
A Paradox
}

Our problem, even if it were not very familiar to teachers already, is easily stated in numbers. We take an English book from a Korean classroom. We divide each dialogue into "utterances", defined, as Bakhtin would define them, as the stretches of dialogue between the moments when the speaker becomes the hearer $(1986$, p. 63$)$. We then count the number of words in each utterance, and we find that the mean length of the utterance in each lesson increases on the average .5 words per year, from 3.2 words per utterance in Third Grade to 4.0 words per utterance in Fifth Grade. Yet when we actually talk to the children, we find a curious paradox. On the one hand, they grow more and more reliant on the textbook for fixed phrases as they age. This ought to make their utterances longer and longer. But on the other, we find them growing more and more laconic in replies. In some cases, syntax disappears, and the child will say very little beyond "yes", "no" and perhaps "fine-thanks-and-how-are-you".

In this paper, we shall explain this paradox and consider some solutions to this problem of disappearing syntax. We begin with two short extracts that show the children using "free choices" in improvising a dialogue and "forced choices" where they are constrained to use a single setting, a single set of characters, and even a single communicative function. In the former extract, the children do little but remember, and remember little but titles of lessons and other fixed phrases from their textbook. In the latter, there is much more creativity and imagination-but there are also much shorter and less accurate utterances. So, as we shall see, the solution to the problem of disappearing syntax cannot simply be more freedom of choice-there must, instead, be a concerted effort to seize power over the very system of constraint.

\section{A One-Week Miracle?}

Consider the following class of children studying English in third grade in a Seoul public school. Two forty-minute lessons a week are required by the state syllabus, which at the time that the data was gathered, also designated a single textbook for the whole country, with an accompanying manual stipulating how lessons are to be conducted. Each lesson has a graduated set of activities from "Look and Listen", to "Listen and Repeat", to "Let's Sing/Chant", culminating in "Let's Play" (usually a rule based game) or "Let's Role Play" (based on an imaginary situation).

The activity from which the data is drawn is a combination of the last two. The children are placed into teams, and the teacher places an imaginary volleyball net down the middle of the class. Each "volleyball team" takes on an imaginary persona from the textbook, and they take turns volunteering utterances, which are then written, by the teacher, on the board. Teams score points when the other team makes an error or when the other team "drops the ball" by not being able to come up with a rejoinder before the count of three (for more details on this game, see Kwon and Kellogg, 2005).

Here, the team names are "Minsu" and "Mina", two Korean siblings from the "Look and Listen" exercise in the textbook. The children are completely free to use any language they know, and they can make up the content of the imaginary characters as they go along. The lesson is recorded using a voice recorder carried by the teacher, and the white board is photographed using a digital camera after it is filled up.

\author{
Minsu: Can you fly? \\ Mina: No, I can't. \\ Minsu: Can you skate? \\ Mina: No, I can't. \\ Minsu: What time is it?
}


Mina: It's eleven twenty five.

Minsu: How many cow? (sic)

Mina: Two cow.

Minsu: How old are you?

Mina: I'm ten.

Minsu: What day is it?

Mina: Tuesday.

Minsu: Can you ski?

Mina: Yes, I can. (Data from Ms. Yun Huijeong)

Why doesn't Minsu know how old his sister is? Why, for that matter, doesn't he know whether or not his sister can skate or fly? The apparently mysterious lack of sibling familiarity is easy to explain. What the children are really doing is neither playing a game nor doing a role play, but reciting the titles and kernel dialogues of almost all of their previous lessons and some of the upcoming ones: "How many cows?", "How old are you?", "What time is it?", and the lesson of the week, which is "Can you swim?"

Now consider the following, recorded just one week later. Here the children are forced to use a single situation (the week's lesson) and even a single language exponent ("Put on your [article of clothing]"). On the other hand, they have been given more discretion in determining the roles. So they have decided that Minsu is an older brother rather than a younger one, and that Mina, the little sister, is attracted to a boy in her class and wants to show off how slim she is. Minsu, already somewhat inclined to sartorial conservatism and somewhat protective, would rather she cover up.

Minsu: Put on your coat.

Mina: No.

Minsu: Outside, cold! (i.e. "It's cold outside.")

Mina: No!

Minsu: What!

Mina: I'm sorry.

Minsu: Put on your glove. (sic)

Mina: Yes.

Minsu: Put on your cap.

Mina: Too big.

Minsu: Put on your sweater.

Mina: Too small.

Minsu (holding up a beautiful scarf): Put on your scarf.

Mina: Yes, please!

Minsu: Put on your pants.

Mina: No, I'm skirt. (i.e. "I want to wear a skirt.")

Minsu: You, inside, play! (i.e. "You must stay inside and play and cannot go out.")

Mina: No!

(Data from Ms. Yun Huijeong)

The incoherence has all but disappeared. Every utterance now appears well motivated and contributes to the developing imaginary situation: at each point it is clear who is saying what to whom and why. We can't attribute this to a miraculous one week increase in English proficiency-not least because a lot of the grammatical well-formedness has disappeared along with the pointlessness. What appears to have occurred is in some ways far more miraculous: Instead of precision and grammatical accuracy ("It's eleven twenty-five") we have relevance and cogency ("Outside, cold!"). Where once there was clausal elaboration ("How old are you?"), we now have what Vygotsky would call purely predicative speech ("Too 
small!"). Negation plays a less prominent grammatical but a more prominent pragmatic role ("No!" in lieu of "No, I can't").

In sum, the sentences have become shorter and the dialogue itself has become longer-that is, the intra-utterance grammatical complexity, which was never fully internalized by the children as meaning, has been unpacked as inter-utterance discourse complexity. Only then can it be folded back into wordings and even sound that are meaningful to the child, and only when this has been done can the wording and sounding be taken for granted, and the whole episode compressed into the now verbalized word meaning "Put on your...." We may easily imagine that henceforth the child's inner voice may lend a somewhat gruff note to this particular utterance.

\section{The Problem of Disappearing Syntax}

Alongside this beautiful picture of the unpacking of meaning as dialogue, we need to look at some baffling, and even terrifying, statistics. We collected texts created by students when they improvised (totaling 1,745 turns) and compared them with the texts created when they simply repeated textbook dialogues (totaling 399 turns). Consent was obtained and data duly recorded from third, fourth, and fifth grade classes for comparison, and then data was taken from every fifth grade class for a whole year. The data was then transcribed. Using a t-test, we found that the textbook dialogues tended to have longer utterances (a mean of 3.6792 words vs. 2.8487 for the improvised dialogues, significant at the level $p<$ .001). Improvised dialogues, on the other hand, had a significantly higher proportion of closed class functor words (e.g. "this" and "your") to total words ("Is this your cap?"). This difference (.6224 vs. .5876) was also significant at the $p<.05$ level. Cohen's $d$ was 0.30703 , which is considered a small or medium effect size. The table below shows the mean length in words per utterance and the standard deviations by grade $(\mathrm{df}=398)$.

Table 1

\begin{tabular}{|c|c|c|c|}
\hline GRADE & $\begin{array}{c}\text { Mean Length in Words } \\
\text { per Utterance }\end{array}$ & $\mathrm{N}$ & Standard Deviation \\
\hline 3 & 3.1705 & 346 & 1.1831 \\
\hline 4 & 2.8828 & 273 & 1.4249 \\
\hline 5 & 2.7416 & 1126 & 1.5921 \\
\hline
\end{tabular}

(Data courtesy of Ms. Yun Huijeong, gathered in the years 2007-2009).

We now return to the transcripts with a qualitative eye. In our subsequent discussion of the transcripts, we take as our definition of "creativity" the ability to say things that the child has never heard before: creative utterances are utterances, which do not appear in the textbook or in the recorded transcript of the lesson.

We immediately notice that there is a decrease in the kind of variations on the textbook language and creative constructions that we saw in our second dialogue above and that the children become increasingly reliant upon the fixed expressions taken straight from the book that we saw in the first dialogue. But this seems highly contradictory. Since the children are using more fixed expressions from the book, and the fixed expressions are growing longer from year to year, shouldn't the children's sentences be growing? 
To resolve this apparent paradox, let us begin by simply trying to describe it more precisely than simply calling utterances either "creative" or "uncreative". At the beginning of the very first dialogue, we saw that the children appear to be repeating whole lesson titles word for word. The first two utterances are the title of the week's lesson and the response that the children have been taught.

Minsu: Can you fly? (Lesson Seven)

Mina: No, I can't. (Lesson Seven)

Following Tomasello's work in first language learning (2003), we might call this use of whole utterances "fixed expressions", though of course we must alter the meaning of the category to fit this foreign language learning context. In this context, we use "fixed expressions" to mean expressions that appear literally, word for word, in the textbook; the child takes them over as they are without changing a single word.

The next two expressions are a little different:

Minsu: Can you skate?

Mina: No, I can't.

Although "Can you swim?" appears in the textbook, there is no use of "Can you skate?" We will call this repetition of a fixed expression with one point of variation an "item-based combination". While "No, I can't" appears in the textbook, it is in the context of swimming and not in the context of skating. So we can see that there is one point of variation. Tomasello (2005) notes that such half-fixed and half-free expressions are a very important step, at least in first language learning. But he also notes that they are limited. Because variation only takes place at a single node, the child can only say things like "Put on your shoes" and not "Take off your gloves". These expressions do not generalize to become a system, and that is why he refers to them as "developmental islands".

Viewed qualitatively, we see that our first dialogue contains only fixed expressions and itembased combinations. However, our second dialogue contains four expressions which are neither fixed expressions nor item-based constructions, namely, "What!", "No, I'm scarf", "Outside, cold!" and "You, inside, play!" Of course, on some level, these are just variations too: "What!" is a variation on "What's this?" "No, I'm scarf" is a variation on "No, I can't" and perhaps also "I'm sorry", "Outside, cold" might come from "Let's go outside" and "It's cold", both of which appear in the lesson, and of course "You, inside, play!" is a funny twist on "outside, cold!" But they are larger, freer variations, involving more than one node of variation. So, again following Tomasello's work in first language acquisition, we will call these apparently original utterances "abstract constructions".

Of course, they are not necessarily abstract in their origins. The creation of a completely original construction by multiple transformations from a memorized chunk of language is possible, and this may indeed be the mechanism by which some abstract constructions might first arise. But when a child says "What!" instead of "What's this?" there is potentially more than mere generalization: there are (at least) two acts of abstraction. First of all, the child is abstracting away the verb phrase "is this", turning a full clause into a minor clause. Secondly, the child is abstracting away intonation as a separate quality, and this act of abstraction allows the child to turn "What's this?" which canonically has a sharply rising (what Halliday and Greaves, 2008 call Tone 2) into "What!" which has a falling, downward intonation (what Halliday and Greaves term Tone 1). This tonal difference turns a question into an indignant exclamationit is an instance of interpersonal metaphor, like the use of a question like "May I have your attention please?" as a command, except in this case it is rather the other way around. Here the child has created 
a system of intonation which will eventually correspond to the lexicogrammatical difference between an interrogative and an exclamative (for an interesting account of how this might take place in first language learning, see Halliday, 2004, p. 44).

Similarly, when the child creates "'No, I'm scarf" from "No, I can't" and "I'm sorry" (if that is how it is indeed created), we have at least potentially more than a set of concrete generalizations. First of all, the child abstracts away "No" from its position as modal adjunct in "No, I can't". Secondly the child abstracts away "sorry" and replaces it with a noun, and to do this the child must also get rid of an article "a" on the noun "scarf". When the child creates "Outside, cold!" from "Let's go outside" and "It's cold" the child is not simply eliding "Let's go" and "it's", the child is also moving "Outside" to what Halliday would call the Thematic position at the beginning of the sentence and giving "cold" the status of Rheme, or comment (see Halliday 2014, pp. 88-92 for more details on Theme and Rheme). As these examples above indicate, they appear to have their own grammar, and involve some abstract notion of "subject", "verb", or "object", or a formula with at least two variables (e.g. " $\mathrm{X}$ is $\mathrm{Y}$ ").

Of course, one could argue-and many linguists will argue-that this is not abstraction but merely elision, and that the result is not a construction but an omission. But this argument assumes that what the child is in the business of constructing is some replica of the adult language. As Halliday points out (2004, p. 29), this is not necessarily the case. What seems much more probable is that replication of the adult language is (as we can see in the fixed expressions and item-based combinations) a subordinate part of a much wider enterprise, namely learning how to mean.

This gives us three categories with which to analyze a larger data base-fixed expressions, itembased combinations, and creative abstract constructions. Our data base is somewhat slanted towards fifth graders, because we collected data every lesson in fifth grade for a whole year in order to see if there was any longitudinal change in the proportions of fixed expressions, item-based combinations, and abstract constructions (there was not). The major categories of interest are given first, followed by "incoherent" contributions which did not make sense and which were ruled out of the game (e.g. "How old are you?" between siblings, already discussed above), "indexical" expressions (mostly "Wow" or "Ha ha!") and "precocious" expressions apparently mined from future lessons in the textbook by hardworking students looking ahead. Here is a breakdown of the data base by grade.

Table 2

\begin{tabular}{|c|l|r|r|}
\hline Grade & Form & Utterances & Percentage \\
\hline \multirow{3}{*}{3} & Fixed Expression & 163 & $47.1 \%$ \\
\cline { 2 - 4 } & Item-based Combination & 109 & $31.5 \%$ \\
\cline { 2 - 4 } & Creative Abstract Construction & 30 & $8.7 \%$ \\
\cline { 2 - 4 } & Incoherent & 11 & $3.2 \%$ \\
\cline { 2 - 4 } & Indexical & 2 & $.6 \%$ \\
\cline { 2 - 4 } & Korean & 7 & $2.0 \%$ \\
\cline { 2 - 4 } & Precocious & 24 & $6.9 \%$ \\
\cline { 2 - 4 } & Total & 346 & $100.0 \%$ \\
\hline \multirow{3}{*}{4} & Fixed Expression & \multicolumn{3}{|c|}{} \\
\cline { 2 - 4 } & Item-based Combination & 149 & $54.6 \%$ \\
\cline { 2 - 4 } & Creative Abstract Construction & 48 & $17.6 \%$ \\
\cline { 2 - 4 } & Incoherent & 40 & $14.7 \%$ \\
\cline { 2 - 4 } & Indexical & 3 & $1.1 \%$ \\
\cline { 2 - 4 } & Precocious & 1 & $.4 \%$ \\
\cline { 2 - 4 } & \multicolumn{3}{|c}{} \\
\cline { 2 - 4 }
\end{tabular}




\begin{tabular}{|c|c|c|c|}
\hline & Total & 273 & $100.0 \%$ \\
\hline \multirow[t]{8}{*}{5} & Fixed Expression & 767 & $68.1 \%$ \\
\hline & Item-based Combination & 124 & $11.0 \%$ \\
\hline & Creative Abstract Construction & 148 & $13.1 \%$ \\
\hline & Incoherent & 3 & $.3 \%$ \\
\hline & Indexical & 11 & $1.0 \%$ \\
\hline & Korean & 2 & $.2 \%$ \\
\hline & Precocious & 71 & $6.3 \%$ \\
\hline & Total & 1126 & $100.0 \%$ \\
\hline
\end{tabular}

As can be seen, the incoherent sentences almost disappear in fourth grade, and so does Korean. But fixed expressions do not; proportionally, they increase rather than decrease, while creative constructions increase from third to fourth grade and then stabilize at about fourteen percent of total utterances. The proportion of item-based combinations declines from nearly a third to under eighteen percent in fourth grade and only eleven percent by fifth. The non-existence of Korean in fourth grade is probably due to the small sample. But we have our paradox: shorter sentences, on the one hand, and more fixed expressions on the other. If the children are adhering more closely to the book, and the utterances in the book are growing longer from year to year, why are the children's utterances growing shorter?

We can explain the paradox of shorter sentences and more fixed expressions quite easily when we look at the most common expressions that the children use in the course of the game, broken down by grade. (See appendix.) As the children age, they appear to favor shorter and simpler fixed expressions rather than longer and more complex creative constructions. It seems that they have learned to pursue a fairly conservative strategy, which is, from the point of view grammatical complexity, not very developmental.

Now, it might appear, at first glance, that this conservative, non-developmental strategy is simply an artifact of the game itself, since creative constructions frequently contain errors and these are penalized by the rules of the game. There are two reasons why we doubt this. First of all, if the children were simply responding to learning the rules of the game, we would expect to see a significant change as soon as the children realize that creative constructions often lead to errors and to losing the point. With data gathered over a whole year's time, we should observe a major change. But we observed no significant change in the fifth grade data that we gathered every week from March until December. Secondly, if the shortening of the utterances was simply a result of the rules of the game then we would expect that the children would go for fixed expressions first-since they are always error free and only resort to an item-based combination when there is no fixed expression that fits. We would also expect that the children would choose item-based combinations before abstract constructions and only resort to the latter when they cannot think of an item-based combination.

This is not what we observe. We number the contributions that the children make from one to fourteen, which is the maximum number of utterances in a dialogue, due to the way the game is structured with the teacher recording utterances on a whiteboard. We then calculate the mean utterance of emergence for each type of expression. This produces a rather surprising result. In spite of the fact that the children are forced, by the rules of the game, to begin with at least one fixed expression from the textbook (because the exercise is one of dialogue continuation rather than complete improvisation), we 
find that item-based combinations appear, on the average, somewhat earlier than fixed expressions; the children do appear to be more eager to use them.

Table 3

\begin{tabular}{|l|c|c|}
\hline Form & Mean utterance of emergence & Standard deviation \\
\hline Fixed expressions & 9.21 & 6.28 \\
\hline Item-based combinations & 8.61 & 6.42 \\
\hline Abstract constructions & 13.84 & 7.83 \\
\hline
\end{tabular}

According to the t-test, the difference between the mean turn of the fixed expression and the item-based combinations is not significant $(p>.1)$, but that between the fixed expressions and the abstract constructions is statistically significant at $p<.001$. Abstract constructions, therefore, do tend to occur significantly later in the improvisation. It appears that while children tend to only resort to creative constructions under pressure and at the very end of the game, they actually tend to use item-based combinations at the same time or even before they employ fixed expressions.

So a better explanation for our paradox of greater reliance on fixed expressions and shrinking sentences is this: the shortening sentences are actually the result of the growing volitional control that we see as the child goes from Tomasello's "fixed expressions" to his "creative abstract constructions". But why would this growing volitional control result in shorter sentences year after year?

One possible explanation is this. The influence of standardized examinations grows stronger and stronger as the child matures, and these tests reward short answers that are $100 \%$ accurate. Longer, more creative answers are far less likely to be error-free, and are therefore not the optimal choice for the child. Of course, in the long run, this is a disastrous choice for everybody. Since we cannot seriously expect children to operate in English with a repertoire of less than a thousand words and only a few hundred basic sentence patterns, our pedagogy may be punishing precisely the item-based combinations and the abstract creative constructions that will be most useful in the wide world outside the classroom.

\section{Local Solutions: Complexity Out of Rebellion}

Korea has a highly centralized educational system which is remarkable impervious to learner needs, teacher demands, empirical research, and sometimes even simple logic (during a heady few months early in the reign of the previous president, it was announced that English would become an official language and all secondary education would be conducted in that medium; this was halted only when it was abruptly realized that nobody would be able to understand anything!).

So it would be otiose to propose curricular change in this paper. Yet we cannot help but note that there are quite simple solutions to the problem of disappearing syntax that emerge on the margins of the data itself, and whose origins lie precisely in the kinds of rebellious, dispreferred responses that the children seem to prefer. Dispreferred responses-that is, responses which are unexpected in some way and need to be accounted for-do tend to be longer and more complex in themselves and require follow ups in ways that preferred responses-that is, responses which are expected and therefore not worth accounting for-do not. (For example, the dispreferred response "Terrible" in response to "How are you?" requires following up in a way that the preferred response "Fine" does not.) 
There are six examples of abstract constructions containing more than one verb, of which two involve subordination (the others are compound sentences constructed using "and" or "but"). Let's look at them. Here Julie is arguing with a talking puppy that has wet her dress:

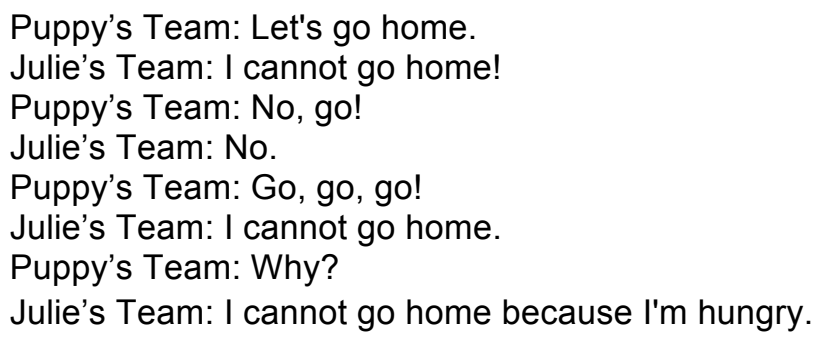

The complex final sentence emerges from the joint elaboration of the word "No!"

What happens when the children do not give a negative response, but instead simply refuse to hear the suggestion? Here one team is playing Mrs. Smith, the teacher, who attempts to detain Jinho. Jinho has a cold and is fleeing to the doctor's office.

Jinho's Team: Bye, Mrs. Smith.

Mrs. Smith's Team: Wait, Jinho.

Jinho's Team: What?

Mrs. Smith's Team: I says 'Wait'.

Our first example of reported speech! Again, it happens because the children are elaborating a dispreferred response. And once again we see that the complexity is a joint construction, not exactly collaborative since it is founded in negation, but certainly highly interactive.

Naturally, moments like these are far from typical, but for that very reason we may suppose that they lie on the cutting edge of the child's development. In next section of this paper, we wish to consider what it is that is developing and how.

\section{Forced Choices, Free Choices}

Traditionally, the development of fluency in a foreign language has been conceptualized in one of two ways: either as the unfolding of the same completely natural "language instinct" that was hypothesized by nativists for first language acquisition (Pinker, 1994) or as the entrainment of habits of behavior, subject to power laws of practice (see especially the work of Nick Ellis, 2002). These two traditional ways have largely defined the discussion of child foreign language learning, even when the century-long marriage of structuralism and behaviorism that followed upon the "Reform" movement of the 1870s fell apart (for an excellent discussion, see A.P.R. Howatt, 1984, pp. 212-228). On one side of the Atlantic, a form of communicative teaching based on structuralism and the innatist ideas of Chomsky developed (e.g. Dulay, Burt, \& Krashen, 1982). On the other, a form of teaching also called "communicative" developed along the lines of "Can Do" specifications and behavioral bands (e.g. Council of Europe, 2001, p. 24).

Little noticed, alongside these traditional ways of regarding what the children are doing in our data as either the unfolding of a natural process or the entrainment of cultural habits, a third choice emerged, that of Halliday's systemic-functional grammar (Halliday with Matthiessen, 2014). In a systemic- 
functional grammar, we understand the data as reflective of sets of choices from a fairly narrow "menu", called a system network. For example, when the child seeks to interact in a role play, the child chooses between talking and acting (or between exchanges of information and exchanges of goods and services). If the child chooses to talk, he or she faces a choice between giving information (canonically by making declarative statements) or getting it (through interrogatives), and if the child chooses to get information, the child then has a choice between asking about polarity (yes-no questions) or requesting missing information (wh-questions). Similar systems networks have been worked out for transitivity structures (that is, material, mental, verbal, and relational processes enacted by the verb and its companions and circumstances) and even for the ordering of elements in a message (that is, their ordering from a Theme that represents the speaker's point of view to a Rheme that represents the hearer-orientation of the message).

But these choices are neither natural nor entrained. They are made quite consciously and deliberately, even creatively, as we see in the "forced choices" of our data. They are then refined, particularly as the child compares them with data in the immediate cultural environment, and it is only here that the "Can Do" descriptors beloved of social-behaviorist approaches become at all relevant, creating solutions, which are intelligent, but no longer novel.

The basic contradiction is this. On the one hand, creativity is not creativity if it comes from outside the child-as we've seen, the "Fixed Expressions" are merely rote repetitions, word for word, from textbook materials, and they are worlds away, structurally, functionally and genetically, from creative abstract constructions. On the other, to ascribe creativity to some inner pre-existing inner creative force is essentially circular: we are explaining creativity by some innate form of creativity, some essentially homuncular form of free will that exists at birth or even before.

In order to trace the true history of creativity in a non-tautological way we must necessarily begin with something that is not creativity. But for Vygotsky, that something is not imitation-or rather, not only imitation-but rather constraint. It is true that initially the constraints do come from the environment; the child is dependent on others for food, warmth, and even transportation, and it is in this way that the child's pragmatic use of language is constructed (Halliday 2004, p. 23). But that is really only half the story; in addition to the pragmatic use of language, the child is reflecting upon and construing representations of his or her own needs, the affordances in her or his environment, and relations between objects and events.

This function, which is not strictly pragmatic, is what Halliday (2004) terms the "mathetic" function. Initially, it simply allows the child a different way of acting on the environment, because the child's utterances, instead of being directed only to others, can be self-directed and can take on a planning function instead (Выготский, 1983, р. 268). But like many new functions (indeed, like the pragmatic function of language which was taken over for mathetic purposes) this new mathetic function does not simply follow along, adapting to reality like an instinct or a habit. This function is capable of anticipating, evading, and even changing reality; it is what makes possible the child's construction of imaginary worlds, one of whose denizens is the child's own idealized behavior, and even the child's sense of self. This is, in turn, exactly how Vygotsky resolves the great paradox: how we can teach creativity through imitation (or, to take an example from moral/ethical education, how we can teach free behavior through telling other people what to do)?

We don't. Instead, what happens is the kind of rebellion that we saw in our data. The child takes control of the means of creativity (or the means of telling other people what to do) and wields them for her 
or his own purposes. These purposes are often quite different from the purposes others may have in teaching the child but which can nevertheless be guided by others through the artificial culture we call play. This guidance cannot, however, take place exclusively through imitation, e.g. the replication of fixed expressions.

First of all, as Vygotsky knew, intelligent imitation even in animals requires that the imitator share the goal of the imitated (Выготский, 1983, р. 131), and when children seize control of the means of creativity they do so for their own purposes and not for the teacher's (e.g. they do so in order to win the game and defeat the other team and not in order to develop their grammar). Secondly, as every child knows, a slavish imitator may be able to play the game but the real goal is not simply to play but to win, and winning a game necessarily involves doing something differently from the loser. The process of developing free will (in language, in art, and even in moral decision making) has certain stages, each of which is divided from the previous stage by a process of selection. It is only at the very bottom of this process, in natural responses and conditioned habits, that we can really talk of natural, that is, unfree selection, viz. constraint. Yet it is precisely on the basis of these unfree selections that higher, freer selections can arise.

When a child, for example stands up for another child being bullied on the playground, we cannot say that the child is obeying instinct-because instinct would make the child run away. Nor can we call this a habit; it may go directly against the grain of getting along with others and avoiding trouble. We cannot say it is intelligent either; the risks are high and the chance of any payoff quite low. What we have to say is that this is an act of free will.

In ontogenetic terms, at least for the first language, development appears to be largely from the bottom up: the child is born into a semiotic world of natural responses (tears and laughter), which provide the raw material for the conditioned habits of early language: But as Halliday (2004) describes the process, it is neither instinct nor adaptation to the external environment that enables this to happen; the child does not unfold a pre-made sound system or imitate a ready-made one from the environment but instead constructs his or her own "child tongue": the naseopharyngealized vowels of crying, for example, become differentiated into vowels on the one hand and consonants on the other, and the prosodics of natural cries become differentiated into the rising intonation of the pragmatic request and the falling intonation of the mathetic statement (Halliday, 2004, p. 145). As the child breaks into lexicogrammar, imitation as a strategy fails even more spectacularly; the utterances the child wants are never the ones that he or she hears or hears and remembers, and only intelligence can help the child in each novel pragmatic situation. Finally, with the mathetic function, we have the ontogenesis of the imaginary situation and of the imaginary self (for the self, like any other meaning-made thing, can neither be inherited nor imitated; it can only be imagined).

These ontogenetic moments in Halliday's account of language construction have equivalents in our microgenetic (Halliday would say logogenetic) data. The natural basis of language is highly conspicuous in the form of the "indexical" expressions (e.g. "Wow!" "Aha!" "Oh!", "Ha ha!" etc.) and above all in the form of laughter. Alongside the sounds of the mother tongue, by now acquired as conditioned habits, laughing, squealing, shouting and shrieking provide the stuff of English prosodics, the intonational tunes which the children use to animate the rote, fixed expressions from the textbook. But just as instinct and even habit failed the child in the acquisition of fixed expressions (English habits are not at all like Korean ones), the imitation of fixed expressions in turn fails the child in the game. 
Borrowing a little from Abraham Maslow's famous "pyramid of needs" (1943), we might portray the Vygotskyan view of what is happening in our data something like this:

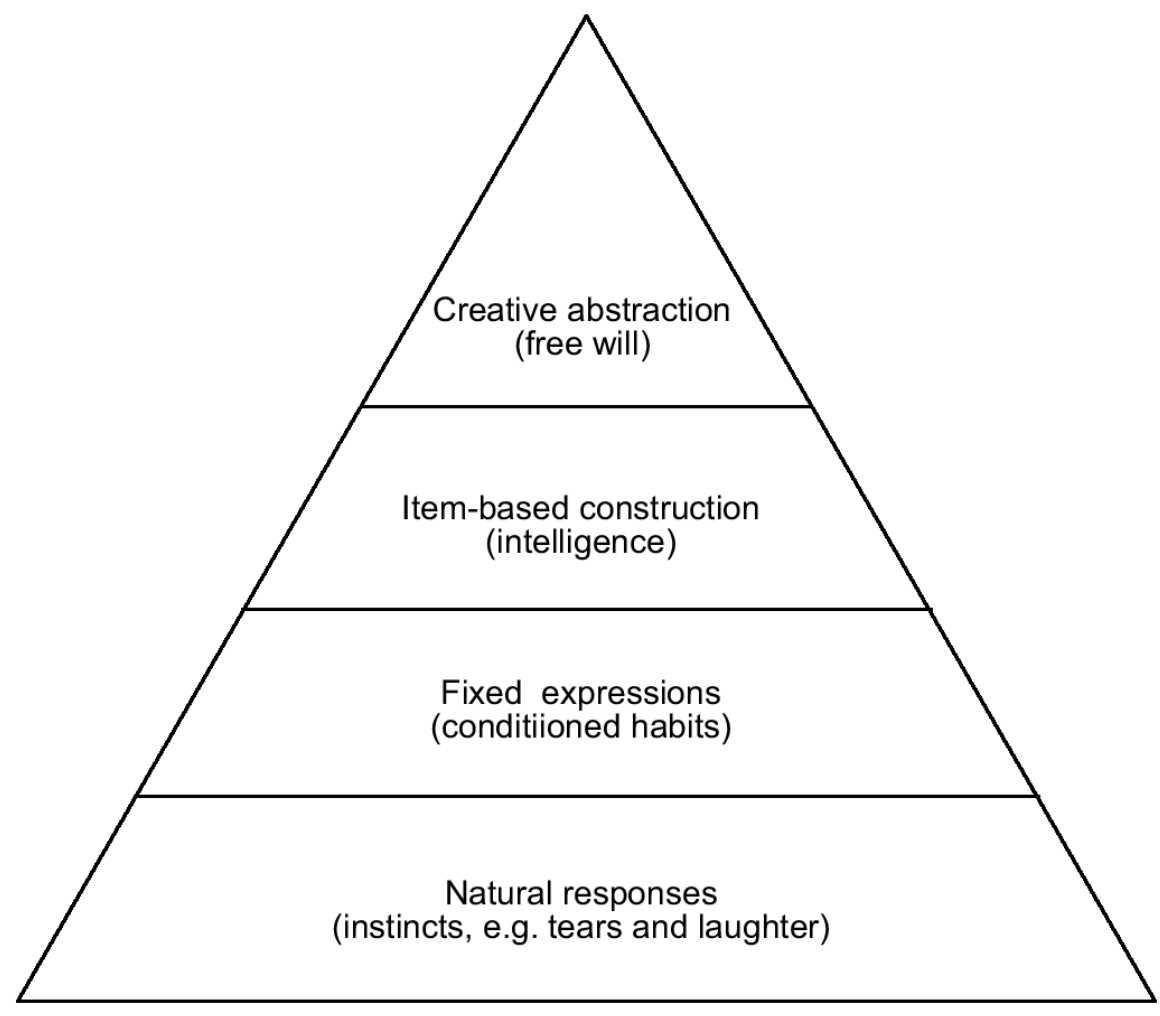

In order to create a coherent dialogue, the Minsu team and the Mina team cannot rely on the conditioned habits memorized from previous and subsequent lesson titles in the book. They must, instead, re-invent the imaginary situation in the book: Mina is now a frolicsome younger sister and Minsu is now an older brother, very conservative and all too familiar with his sibling's flirtatious ways. This imaginary situation is undoubtedly based on the characters, the situation, and even the specific language ("Put on your ....") that we find in the textbook; but it cannot be said to be a conditioned habit; since the specific problem is novel. By reimagining the characters the children have created a problem that cannot solved by rote methods and instead requires, at the very least, the use of item-based combination ("Put on your coat/glove/cap/sweater/scarf/pants!"). The other team is now confronted with one item-based combination after another. Because her negative response is repeated, it can be truncated (not "No, I won't" but simply "No!"). But nay-saying is a passive exercise that ill suits the vivacious character Mina, and she begins to give reasons for her refusal ("Too small", "too big"). She even responds to the beautiful scarf with an enthusiastic "Yes, please!", which is hardly an example of truncation. But none of this allows her what she really wants from the dialogue, which is the opportunity to show off her attractive legs. Only the creative abstract construction "No, I'm skirt" has the power to do this.

"No, I'm skirt" is of course not a habit; still less is it an instinct. But it is also not exactly an "intelligent" solution. First of all, it's not economical; a fixed "No!" would suffice and an item-based combination like "I don't like pants" could be reused in subsequent utterances (and, as we've seen, economical solutions like these do account for the problem of disappearing syntax). Secondly, it's not 
adaptative: the chance of error is high (and in fact Mina does make an error which, if the teacher were not enjoying the repartee so much, would put an end to the game and award the other side a point). Thirdly, it is not strategic; it lays Mina open to a very simple follow-up "Why?" which would require some difficult explaining (and in fact the children often do use "Why?" or "Why not?" as a way of "spiking" in this game of verbal volleyball, precisely because it requires a full clause in reply). What we have to say is that "No, I'm skirt" is not only a creative abstract construction, in that it has its own model of a grammar that is quite different from English grammar, but also an act of free will. More, what we may say is that this act of free will emerges precisely out of the forced choices imposed on poor Mina by her tyrannical brother and by the difficult language game she is learning to play with such creativity and with such imagination.

In his book "The History of the Development of the Higher Psychological Functions", recently translated into Korean as 어린의 자기행동 숙달의 역사와 발달 ('History and Development in the Child's Self-mastery of Behavior", 비고츠키, 2013, 2014), Vygotsky presents a series of experiments in which the child is given a long list of words to memorize. The child is offered a set of pictures, which may offer some kind of mnemonic structure. Some of the mnemonic structures are quite obvious (e.g. a picture of a camel will help the child remember the noun "death", and a picture of a lion will help the child remember the word "shoot"). When the child is given a "free choice" of pictures, these are the choices that the child appears inclined to make. But in other cases the child is forced to create his or her own mnemonic structure (e.g. the child must use a picture of a crab in order to remember the word "theatre"). In these cases, Vygotsky discovers, children can come up with highly innovative structures (e.g. the child imagines the crab admiring beautiful stones at the bottom of the sea as if at the theatre) and these turn out to be more durable-and even more efficient in recovering the precise word-than the more conventional sort (Выготский, 1983, р. 242).

Vygotsky explains. The "free choice" offered the child is in fact not free at all; the child is only given a menu of conventional associations from which to choose. The story of the camel's death and the shooting of the lion are not the child's stories but only linguistic habits recollected from other stories. In contrast, the choice forced upon the child is truly free: the child can create his or her own mnemonic link. The story of the crab's theatre is a story, which the child freely made up, and so the link between the crab and the theatre gives the child a more active form of remembering. It seems plausible that this more active form of remembering is agnatic to the kind of linguistic creativity we see when the children in our data are forced to use a single structure such as "Put on your..." rather than given a free choice of structures from which to choose, and when they respond by experimentally enacting an internal function, in this case the pragmatic use of the language, as an experimental drama between imaginary people.

A final, somewhat self-reflexive note: this paper has, in the course of the normal process of peer review at this journal, passed through many forced choices, some of which were voluntarily undertaken, and some of which were made under pressure from the editors. For example, in their lengthy decision over-ruling the majority of the reviewers and rejecting this manuscript, the managing editors insisted that "the whole 'fun' of play lies in the fact that the rules that are upheld are devised by the players." Since the

\footnotetext{
${ }^{2}$ Editors' Note: The above is a quote from my (Ana Marjanovic-Shane) editorial comments on the margins of the manuscript (draft \#1), dated 2014-02-28. The full comment reads: " $\mathrm{Hm}$, The term 'forced' is problematic for me here - because it usually implies force that comes not from intrinsic motivation but an outside force. However, the whole 'fun' of play is in the fact that the rules that are upheld are devised by the players. Yes, there is a fact that each situation 'affords' some and does not 'afford' other patterns of behavior and decision (Gibson), but since in play, these situations are imaginary, the 'affordance' is not quite 'forced' - what do you think? ... So in itself, to say 'forced' is a particular interpretation of what play means - and it might be great for you to discuss it since you are using it in that way. Otherwise, it is not quite justified, from our point of view."

Thoughts expressed in that remark, were finalized in the following paragraph in the Editorial decision dated 2014-02-28: "Another concept that we find very promising is the concept of the tension between what you call 'forced choices' afforded by the context of an imagined situation (as in Gibson's view of affordance) on one side; and on the other, the feeling of freedom that makes play so
} 
rules of this game were not devised by the players but rather by the author, this would suggest that the play was not fun, something that is really at variance with the fact that the game continued to be demanded by the children in every single lesson for the rest of the year. In their second, conditional acceptance of this paper, the editors wrote that our analysis of the data has tended to obscure "the feeling of freedom that makes play so appealing to the players". ${ }^{3}$ It appears, therefore, that the editors would like us to emphasize the "free" in free will: that it is freedom which makes play attractive to the players.

This recommendation is marked "optional" by the managing editors, which has the unfortunate effect of making all of their other recommendations appear binding. But this optional recommendation seems unwarranted to us: it seems to us more likely that it is the "will" in free will that motivates the children; it is the skillful exercise of will which allows them to win the game. We saw that in the first data extract, when the children were absolutely free to choose any language they knew and when they were able to build up the characters and the situation as they went along, the game was nonsensical and not motivating; in the second data extract, when the children forced themselves to stick to the situation in the textbook and to relatively fixed characters (and when Minsu forced sartorial choices on poor Mina), the game became much more creative, both in a literary and in a linguistic sense.

Like the rules the game imposed on our learners, none of the recommendations made by the reviewers or editors were devised by the author. Nevertheless, some of them we undertook readily and willingly. Others we accepted only after our paper was rejected and with the understanding that our voice would not be heard unless it could be brought more into harmony with that of the editors. Here, perhaps perversely, we do find ourselves in full agreement on the essential inseparability of freedom and will. Some forced choices, voluntarily taken and mastered from within, may be immensely fruitful, while others, merely submitted to and imposed from afar, are stifling and sterile, and may even strangle the very syntax that they purport to promote.

\section{References}

비고츠키, L.S. (2013). 어린의 자기행동 숙달의 역사와 발달, I. 서울: 살림터.

비고츠키, L.S. (2014). 어린의 자기행동 숙달의 역사와 발달, II. 서울: 살림터

Выготский Л. С. 1983. Собрание сочинений Т.з. Под ред. А. М. Матюшкина. М.: Педагогика.

Council of Europe, (2001). Common European Framework for Languages: Learning, teaching, assessment. Cambridge: Cambridge University Press.

Dulay, H., Burt, M., and Krashen, S.D. (1982). Language Two. New York: Oxford University Press.

appealing to the players. This tension between the 'enforced' rules and the feeling of freedom is an incredibly fruitful field for exploration in education and we would encourage you to develop this concept further based on the data you collected." The full text of the Editors' letter of decision dated 2014-02-28 can be found on the Dialogic Pedagogy Journal Community Space. It is visible only to the DPJ members at http://dpj.pitt.edu/ojs/index.php/dpj2/comment/view/66/0/84. Furthermore, all peer reviews are also accessible to the Journal members at the DPJ Community Space at http://dpj.pitt.edu/ojs/index.php/dpj2/article/view/66.

${ }^{3}$ Editor's Note: The full paragraph in the Editors' letter of decision dated 2014-05-16 from which the author quotes, reads as follows: "[Optional - but potentially enhancing your manuscript]. We stay with our earlier remark that we find very promising your emerging analysis of the tension between what you call 'forced choices' afforded by the context of an imagined situation (as in Gibson's view of affordance) on one side; and on the other, the feeling of freedom that makes play so appealing to the players. This tension between the 'enforced' rules and the feeling of freedom is an incredibly fruitful field for exploration in education and it seems to be very relevant for the data that you describe. This is especially interesting in the light of your analysis of 'rebellion' and 'free will', that at this point seem to be somewhat obscured by other aspects of your analysis. Of course, it will be up to you if you want to add more discussion of this issue." The Editors' letter of decision dated 2014-05-16 can be found on the Dialogic Pedagogy Journal Community Space. It is visible to the DPJ members at http://dpj.pitt.edu/ojs/index.php/dpj2/comment/view/96/0/136. Furthermore, all peer reviews are also accessible to the Journal members at the DPJ Community Space at http://dpj.pitt.edu/ojs/index.php/dpj2/article/view/96. 
Ellis, N. C. (2002). Frequency effects in language acquisition: A review with implications for theories of implicit and explicit language acquisition. Studies in Second Language Acquisition, 24, 143-188.

Halliday, M.A.K. (2004). The Language of Early Childhood. London: Continuum.

Halliday, M.A.K. and Greaves, W.S. (2008). Intonation in the Grammar of English. London: Continuum.

Halliday, M.A.K. with Matthiessen, C.M.I.M. (2014). Halliday's Introduction to Functional Grammar. London: Routledge.

Howatt, A.P.R. (1984). A History of English Language Teaching. Oxford: Oxford University Press.

Kwon, M.-S. and Kellogg, D. (2005). Teacher talk as a game of catch. The Canadian Modern Language Review / La revue canadienne des langues vivantes, 62 (2) 335-348.

Maslow, A.H. (1943). 'A theory of human motivation.' Psychological Review, 50 370-396.

Pinker, S. (1994). The Language Instinct. New York: Harper Collins.

Tomasello, M. (2003). Constructing a Language: A Usage Based Theory of Language Acquisition. Cambridge, MA and London: Harvard University Press.

\section{(c)) EY}

New articles in this journal are licensed under a Creative Commons Attribution 4.0 United States License.

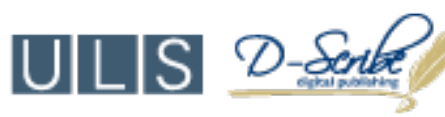

This journal is published by the University Library System, University of Pittsburgh as part of its D-Scribe Digital Publishing Program and is cosponsored by the University of Pittsburgh Press. 